\title{
N-terminal Pro-B-Type Natriuretic Peptide and Malnutrition in Patients on Hemodialysis
}

\author{
Jacques Ducros, ${ }^{1}$ Laurent Larifla, ${ }^{2,3}$ Henri Merault, ${ }^{1}$ Valérie Galantine, ${ }^{1}$ \\ Valérie Bassien-Capsa, ${ }^{3}$ and Lydia Foucan (D) $^{2,3}$ \\ ${ }^{1}$ Service de Néphrologie, Centre Hospitalier Universitaire, Guadeloupe, France \\ ${ }^{2}$ Service de Cardiologie, Centre Hospitalier Universitaire, Guadeloupe, France \\ ${ }^{3}$ Equipe de recherche Epidémiologie Clinique et Médecine sur le Risque Cardio métabolique, ECM/LAMIA, EA 4540, \\ Université des Antilles, Centre Hospitalier Universitaire, Guadeloupe, France
}

Correspondence should be addressed to Lydia Foucan; lfoucan29@yahoo.com

Received 30 December 2019; Accepted 11 February 2020; Published 5 March 2020

Academic Editor: Jaime Uribarri

Copyright (c) 2020 Jacques Ducros et al. This is an open access article distributed under the Creative Commons Attribution License, which permits unrestricted use, distribution, and reproduction in any medium, provided the original work is properly cited.

\begin{abstract}
Natriuretic peptides, brain natriuretic peptide (BNP), and N-terminal probrain natriuretic peptide (NT-proBNP) are mainly known as diagnostic markers for heart failure with high diagnostic and prognostic values in the general population. In patients who are undergoing hemodialysis (HD), changes in NT-proBNP can be related to noncardiac problems such as fluid overload, inflammation, or malnutrition and can also be influenced by the dialysis characteristics. The current review aimed to summarize findings from studies on the association between NT-proBNP and malnutrition in HD patients. Articles published after 2009 and over a ten-year period were considered for inclusion. We first briefly discuss the traditional functions of NT-proBNP, and after, we describe the functions of this prohormone by focusing on its relation with protein energy wasting (PEW) in HD patients. Mechanisms that could explain these relationships were also discussed. Overall, 7 studies in which the investigation of the relations between NT-proBNP and nutritional status in HD patients were among the main objects were taken into account. NTproBNP levels correlated with several factors described in the 4 categories of markers indicative of PEW (body mass and composition, muscle mass, biochemical criteria, and dietary intakes) and/or were associated with PEW. Interactions between several parameters could be involved in the association between NT-proBNP and malnutrition with a strong role of weight status. NT-proBNP is elevated in HD patients and is associated with malnutrition. Nevertheless, the prognostic value of NT-proBNP on nutritional status should be evaluated.
\end{abstract}

\section{Introduction}

Uremic malnutrition, also called malnutrition inflammation complex syndrome or protein energy wasting, corresponding to a decrease in energy and body protein, is a common problem in patients with end-stage renal disease (ESRD) undergoing HD and has been consistently associated with mortality in different populations [1-5].

Brain natriuretic peptide (BNP) is synthesized mainly in the heart as a proBNP that is further cleaved into bioactive BNP and biologically inactive NT-proBNP [6].
Both BNP and NT-proBNP are released in response to changes in pressure inside the heart that are related to heart failure and other cardiac problems. Thus, BNP and NT-proBNP are mainly known as cardiac biomarkers with high diagnostic and prognostic values [7-9] with widespread use in cardiac diseases [10]. In HD patients, changes in NT-proBNP can be related to noncardiac problems such as fluid overload, inflammation, or malnutrition. In this line, NT-proBNP was recently associated with 2-year mortality from both cardiovascular and noncardiovascular origins in 1,310 prevalent chronic HD patients [3]. 
The current review aimed to summarize findings from studies on the association between NT-proBNP and malnutrition in HD patients.

\section{Methods}

For this review, we reviewed the literature using PubMed, Medline, and Scopus with the following search terms: $\mathrm{N}$-terminal probrain natriuretic peptide (NT-proBNP), nutritional status, malnutrition, and hemodialysis (HD) in humans. We also searched in the selected articles and took into account some of the relevant references cited by the authors. Mechanisms that could explain these relationships were also discussed while also taking the results of some animal studies into account.

Articles published after 2009 and over a ten-year period, in adults ( $>18$ year of age), were considered for inclusion.

We first briefly discuss the characteristics and traditional functions of NT-proBNP, and after, we describe the functions of this prohormone by focusing on its relation with protein energy wasting (PEW) in patients undergoing maintenance HD.

\section{Results}

During the period taken into account in this review, we found 7 studies in which the investigation of the relations between NT-proBNP and nutritional status in HD patients were among the main objects [11-17]. These studies are summarized in Table 1.

\section{Discussion}

4.1. NT-proBNP Levels in HD Patients. The levels of the prohormone vary according to the population studied. NTproBNP is cleared by the kidney and, in patients with CKD, especially those on $\mathrm{HD}$, levels of NT-proBNP are usually increased as a consequence of increasing secretion and decreasing renal clearance [17].

Thus, elevated levels of the prohormone are often observed in HD patients without clinical evidence of cardiovascular disease. These high NT-proBNP levels in patients with renal dysfunction $[11,12,18-20]$ were higher than in individuals with normal renal function.

\subsection{Factors Other than Cardiac Status That Influence NT- proBNP Levels in HD Patients}

(i) The influences of age, gender, body mass index (BMI), time of the dialysis session during the week, time of measurement of NT-proBNP before or after a hemodialysis session, dialysis characteristics, and membrane type have been reported [21-24].

(ii) In some studies, blood concentrations of NTProBNP were associated with hypervolemia or fluid overload [11, 25-28]. Results of bioimpedance monitoring, a tool that defines the influence of fluid overload in body mass index and clinical dry weight assessment, can also be affected by malnutrition with loss of cell mass [26].

(iii) Inflammation also influences NT-proBNP levels $[13,17,29]$.

4.3. Assessment of Malnutrition. Studies on maintenance of $\mathrm{HD}$ patients have reported the association between NTproBNP levels and malnutrition by subjective global assessment (SGA), malnutrition-inflammation score (MIS), or markers defined in the International Society of Renal $\mathrm{Nu}$ trition and Metabolism (ISRNM) nomenclature [11-17].

Globally, SGA is a tool that uses 5 components of a medical history (weight change, dietary intake, gastrointestinal symptoms, functional capacity, and disease and its relation to nutritional requirements) and 3 components of a brief physical examination (signs of fat and muscle wasting, nutrition-associated alterations in fluid balance) to assess nutritional status [30]. The MIS has 10 components, each with four levels of severity ranging from 0 (normal) to 3 (very severe). The sum of all components ranges from 0 to 30. Higher scores reflect more severe malnutrition and inflammation [31].

The practice guidelines and criteria for evaluating nutritional status in ESRD patients recommend the use of nomenclatures for $\operatorname{PEW}[32,33]$. In the nomenclature, proposed by the ISRNM [32], several parameters among four established categories (body mass and composition, muscle mass, biochemical criteria, and dietary intakes) are indicative of PEW in individuals with kidney disease. At least 3 out of the 4 listed categories must be satisfied for the diagnosis of kidney disease-related PEW.

4.4. Relations between NT-ProBNP and Nutritional Status. To study these relationships, we first focused on the relation between the main parameters described in the 4 categories of factors for PEW identification according to the ISRNM nomenclature, and after, we considered the relation with malnutrition status in each of the studies.

4.4.1. NT-proBNP and Body Mass and Composition. Lower BMI, body fat, and unintentional weight loss over time are included in this category of nutritional markers in the ISRNM nomenclature.

(1) Body Weight-BMI. Inverse relationships between BMI and circulating levels of NT-proBNP have been demonstrated, and lower BMI has been associated with higher NTproBNP levels in subjects with and without heart failure $[25,34-38]$ as in patients with ESRD undergoing HD [11-16, 27, 39].

(2) Weight Loss. Weight loss is known to increase natriuretic peptide levels [40-43]. In HD patients, simple correlations between log NT-proBNP and percent weight loss have been found [26]. NT-proBNP levels were also associated with unintentional weight loss ( $-5 \%$ over 3 months) in another 
TABLE 1: Summary of studies on relationships between NT-proBNP and protein energy wasting in maintenance hemodialysis.

\begin{tabular}{|c|c|c|c|c|}
\hline Authors & Country & $\begin{array}{l}\text { Number of } \\
\text { HD subjects }\end{array}$ & $\begin{array}{l}\text { Study design } \\
\text { Assessment of } \\
\text { malnutrition } \\
\text { Men/women } \\
\text { Age (years) }\end{array}$ & NT-proBNP levels \\
\hline
\end{tabular}

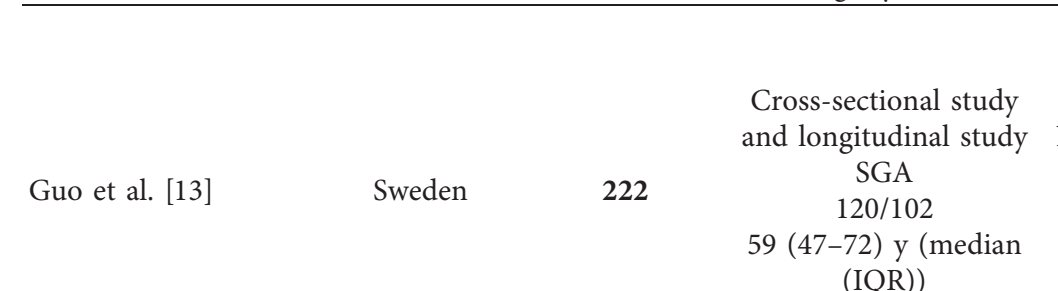

$(\mathrm{IQR}))$
Values (median (IQR)): 11,609 (4,581-35,000) with wasting signs $(\mathrm{SGA}>1) 5,671(1,909-17,141) \mathrm{pg} / \mathrm{ml}$ in those without

Negatively associated with nutrition markers, including serum albumin, IGF-1, handgrip strength, serum creatinine, and body weight

Higher values $(>9,761 \mathrm{pg} / \mathrm{ml})$ associated with PEW (SGA > 1)

Independently predicted PEW

Nonsurvival had a poorer nutritional status

Cross-sectional study
Indices of nutritional Values (range): $403-35,000 \mathrm{pg} / \mathrm{ml}$

$\begin{array}{lccc}\begin{array}{l}\text { Bednarek-Skublewska } \\ \text { et al. [11] }\end{array} & \text { Poland } & \mathbf{9 7} & \begin{array}{c}\text { Indices of nutritional } \\ \text { status and BIA } \\ 57 / 40 \\ 20-92 \mathrm{y} \text { (range) }\end{array} \\ & & \\ \text { Lee et al. [15] } & & \begin{array}{c}\text { Cross-sectional study } \\ \text { SGA and MIS } \\ \end{array} \\ & \text { Korea } & 44 & 53.9 \pm 9.2 \mathrm{y}(\text { mean } \pm \text { SD) }\end{array}$

Negatively correlated with BMI, albumin, and transferrin

Elevated in patients with intensive catabolism

Values (median (IQR)): 4,342 (1,582-22,304) pg/ml in well-nourished $24,807(11,435-44,127) \mathrm{pg} / \mathrm{ml}$ in malnourished

Negatively correlated with fat mass Positively correlated with MIS

Elevated in those with malnutrition

Values (median (IQR)): 8,946 (2,909-26,571) pg/mL

$12,932(5,658-35,001) \mathrm{pg} / \mathrm{mL}$ with PEW (SGA > 1) 6,092

$(2,248-17,670) \mathrm{pg} / \mathrm{mL}$ without PEW

Associated with malnutrition (SGA $>1$ )

\begin{tabular}{|c|c|c|c|}
\hline Snaedal et al. [17] & Sweden & 211 & $\begin{array}{c}55 / 156 \\
66(51-74) \text { y (median } \\
\text { (IOR) })\end{array}$ \\
\hline
\end{tabular}

Changes in NT-proBNP associated with change in nutritional status

Worse nutritional status was significantly related to increased variability

Values: (mean \pm SD): 6,098 \pm 19,659

Longitudinal study Indices of nutritional status and BIA $206 / 115$

$65 \pm 21$ y $($ mean $\pm S D)$
NT-proBNP correlated negatively with practically all nutritional indices

Cohort divided into NT-proBNP quartiles (with lowest values in Q1)

BMI and fat tissue index decreased across NT-proBNP quartiles; highest albumin level was present in Q1 Lowest total cholesterol level in Q4

Values (median (range)): 2,910 (465-78,400) pg/ml Associated with muscle loss in malnourished HD patients

Longitudinal study
SGA
$149 / 89$
$64 \pm 13$ y $($ mean \pm SD $)$

Independently predicted the decreased change of LBM and the index of muscle loss

Higher NT-proBNP levels: Decreased levels of creatinine, creatinine index as well as \%CGR, lower total fat mass, and LBM and higher frequency of malnutrition

Values (range): 125-33,144 pg/ml (median (IQR)):

6,243 (1833-18,721) pg/mL with PEW 2,132

$(1,100-5,200) \mathrm{pg} / \mathrm{mL}$ without PEW

Elevated in those with BMI $\leq 23 \mathrm{Kg} / \mathrm{m} 2$ ), albumin $\leq 38 \mathrm{~g} /$

L, creatinine,
$\leq 818 \mu \mathrm{mol} / \mathrm{L}, \mathrm{nPCR} \leq 0.8 \mathrm{~g} / \mathrm{kg} / \mathrm{d}$ ) and PEW (at least 3

Cross-sectional study

ISRNM nomenclature for PEW $112 / 95$

$64 \pm 13$ y $($ mean $\pm S D)$ among the 4 parameters)

Negatively correlated with BMI and nPCR Increased with the increasing of the PEW marker number

Values $\geq 6243 \mathrm{pg} / \mathrm{mL}$ independently associated with PEW 
sample of HD patients [12], and positive correlation between NT-proBNP and IDWG was also reported [11].

(3) Body Fat. In HD patients, fat tissue index decreased across NT-proBNP quartiles [16], and lower total fat mass was found in those with greater NT-proBNP values [14]. These authors also investigated NT-proBNP and lean body mass (LBM) at baseline and at 12 months. LBM over 12 months was significantly decreased above the threshold of $\log$ NT-proBNP with 8.5 being the equivalent of $5,000 \mathrm{pg} /$ $\mathrm{mL}[14]$.

4.4.2. NT-proBNP and Muscle Mass. Assessment of nutritional status and especially evaluation of muscle mass is essential for the identification of patients at risk for the development of PEW [44]. Indirect measures of muscle mass such as serum creatinine (before a HD treatment), creatinine appearance, creatinine generation rate (\%CGR), and creatinine index have been proposed. High NT-proBNP has been associated with decreased levels of creatinine, decreased creatinine index, or \% CGR in HD patients [12-14].

4.4.3. NT-proBNP and Biochemical Criteria. Some biochemical indicators have been proposed for the diagnosis of PEW, and serum albumin, serum prealbumin (transthyretin), and cholesterol have been studied as nutritional markers in CKD patients [32]. Negative relationships were found between serum albumin and NT-proBNP levels by some authors $[11,13,16,26]$ and not by some others [14]. But low serum albumin concentration is not sufficient for the diagnosis of PEW, although it is often present in this condition [32]. Natriuretic peptides also affect lipid metabolism and plasma cholesterol $[16,45]$.

4.4.4. NT-proBNP and Dietary Intakes. In the ISRNM nomenclature, low dietary intake was considered in the presence of unintentional low dietary protein intake $<0.8 \mathrm{~g} /$ $\mathrm{kg}$ /day for at least 2 months for dialysis patients or unintentional low dietary energy intake $<25 \mathrm{kcal} / \mathrm{kg} / \mathrm{day}$ for at least 2 months [32]. The normalized protein catabolic rate (nPCR) has been proposed as a useful measure for dietary protein intake and ultimately for nutrition. The HD procedure can enhance protein catabolism owing to dialytic losses of protein and amino acids and to the inflammatory response to blood-dialyzer interaction $[46,47]$. The nPCR is a parameter of intensive catabolism. In HD patients with intensive catabolism, nPCR was one of the 4 parameters influencing serum NT-proBNP [11]. Simple negative correlation between log NT-proBNP and nPCR was also found in another study [12], but no relation was found by other authors [14].

4.4.5. NT-proBNP and Protein Energy Wasting. The 7 studies in which the investigation of the relations between NT-proBNP and nutritional status in HD patients were among the main objects are summarized in Table 1.
In $222 \mathrm{HD}$ patients, the association between NTproBNP, PEW, and inflammation was evaluated. NTproBNP was analyzed in plasma by an immunometric assay. Patients presenting with an SGA score of 2-4 were defined as malnourished. A NT-proBNP level above $9,761 \mathrm{pg} / \mathrm{ml}$ was associated with PEW even following adjustment for age, dialysis vintage, inflammation, and Davies score [13].

In $97 \mathrm{HD}$ patients, the relationship between serum level of NT-proBNP and nutritional status, inflammation, and hydration was investigated. NT-proBNP was measured by an immunoassay. The nutritional status was evaluated with specific markers including BMI, albumin, and nPCR. NTproBNP was only moderately associated directly with hydration status but was extremely elevated in patients with intensive catabolism [11].

In $44 \mathrm{HD}$ patients, nutritional status was assessed using subjective SGA and MIS. NT-proBNP was measured by immunoassay, malnutrition was accompanied by volume overload and associated with increased log NT-proBNP, and these levels were independently associated with increased left ventricular mass index [15]. The authors suggested a possibility that nutritional status may affect ventricular remodeling in hemodialysis patients [15].

A prospective study was performed in $211 \mathrm{HD}$ patients to analyze NT-proBNP variability and the factors predicting this variability. Malnutrition was one of the studied factors. NT-proBNP was measured by an immunometric assay. Longitudinal changes in NT-proBNP were associated with changes in nutritional status. Patients with wasting and patients with congestive heart failure had significantly higher NT-proBNP levels than patients without these conditions [17].

A study aiming to establish the usefulness of NTproBNP for hydration assessment and the relation of NTproBNP with the nutritional state and prognosis of survival was conducted in $321 \mathrm{HD}$ patients. NT-proBNP was measured by immunoassay. Bioimpedance analysis was used. Patients were classified according to quartiles of NTproBNP. NT-proBNP correlated negatively with practically all nutritional indices including serum albumin, cholesterol, and BMI. The highest albumin level was present in Q1 $(4.10 \pm 0.63 / 3.99 \pm 0.51 / 3.90 \pm 0.62 / 3.97 \pm 0.78 \mathrm{~g} / \mathrm{dl} ; P=0.006)$. The TC level was the lowest in Q4 $(190 \pm 60 / 169 \pm 56 / 173 \pm 51$ / $153 \pm 56 \mathrm{mg} / \mathrm{dl} ; P=0.002)$. But, although the data showed a relation of NT-proBNP with nutritional status, this link was less conspicuous than the link between NT-proBNP and hydratation [16].

In a prospective observational study with one-year follow-up in a cohort of prevalent HD patients $(n=238)$, NT-proBNP levels were measured by fully automated electrochemiluminescence. Nutritional status and changes in muscle mass were evaluated by subjective global assessment, \%CGR, and creatinine index. NT-proBNP was significantly higher in HD patients with PEW. Prevalent HD patients with higher NT-proBNP (NT-proBNP $\geqq 5,760 \mathrm{pg} /$ $\mathrm{mL}$ ) showed a high prevalence of malnutrition ( $30 \%$ vs $11 \%$ for those with lower NT-proBNP levels, $P=0.0002$ ), decreased levels of creatinine, and decreased creatinine index. The authors suggested that compared with serum albumin, 
measurement of NT-proBNP could be a superior predictor of muscle loss in patients on HD. Patients with the highest NT-proBNP also showed a high prevalence of cardiac events and malnutrition [14].

The association between PEW and NT-proBNP was evaluated in a cross-sectional study performed in 207 AfroCaribbean HD patients. One component in each of the 4 categories for the wasting syndrome (according to the ISRNM nomenclature) was retained: serum albumin $<38 \mathrm{~g} /$ $\mathrm{L}, \mathrm{BMI}<23 \mathrm{~kg} / \mathrm{m}^{2}$, serum creatinine $<818 \mu \mathrm{mol} / \mathrm{L}$ (for this sample of Afro-Carribean HD patients), and $\mathrm{nPCR}<0.8 \mathrm{~g} /$ kg/day. NT-proBNP was assessed using a chemiluminescence immunoassay. The frequency of individuals with low serum albumin level was higher in those with NTproBNP $\geq 6,243 \mathrm{pg} / \mathrm{mL}$ than in the others $(59.6 \%$ vs $43.2 \%$, $P=0.041)$. A negative correlation between log NT-proBNP and nPCR was also found $(r=-0.15 ; P=0.028)$. High levels of NT-proBNP $(\geq 6,243 \mathrm{pg} / \mathrm{mL})$ were independently associated with PEW. NT-proBNP concentrations increased with PEW component number (on the basis of 1 in each of the 4 listed categories of PEW markers) [12].

In some other studies, authors found associations between NT-proBNP and signs of wasting, but the investigation of these relations was not the main objects in these studies $[26,48]$.

4.5. Hypotheses to Explain the Relation between NT-proBNP and Protein Energy Wasting. Several hypotheses have been proposed concerning the association between high NTproBNP and PEW.

(i) A direct effect of PEW on the level of NT-proBNP by affecting ventricular remodeling in $\mathrm{HD}$ patients has been suggested [15].

(ii) Complex interactions between NT-proBNP, malnutrition, inflammation, and fluid overload have been reported in HD patients $[17,49,50]$. In addition, bioimpedance results affected by fluid overload can also be affected by malnutrition

(iii) Several parameters among 4 established categories (body mass and composition, muscle mass, biochemical criteria, and dietary intakes) for the definition of PEW according to ISRNM are separately associated with NT-proBNP. Interaction between some of these parameters could be involved in the association between NT-proBNP and malnutrition with a strong role of weight status [12]. In fact, HD patients with greater protein and energy intakes usually have a greater BMI [5] and the inverse. Hypoalbuminemia is the result of the combined effects of inflammation and inadequate protein and caloric intake [51] that could lead to low BMI. Creatinine level is a surrogate of muscle mass in HD patients [52]. Anorexia and low nutrient intake could also lead to lower muscle mass, lower creatinine levels, and lower BMI.

(iv) Other hypothesis, suggested in patients without CKD, might be involved in HD patients.
Adipose tissue could also play an important role. It has been shown that NP display a lipolytic effect in adipose tissue $[53,54]$ and enhance the oxidative capacity of human skeletal muscle [55]. A heart adipose tissue connection has been suggested [56] as well as a link between NT-proBNP, PEW, and the appetite-modulating hormone ghrelin. Ghrelin and acyl ghrelin levels are associated with nutritional markers in HD patients [57], and low acyl ghrelin level was found associated with high NTproBNP in male HD patients [57]. Plasma des-acyl ghrelin levels were significantly higher in HD patients than in controls and in anorexic HD patients than in nonanorexic [58] suggesting that des-acyl ghrelin, which induces a negative energy balance, could be involved in the complex pathogenesis of anorexia that is frequently found in HD patients $[58,59]$.

\section{Conclusions}

In summary, the data suggest that NT-proBNP correlates with the indices of protein energy wasting and malnutrition. Therefore, this marker seems to be useful in the evaluation of nutritional status in hemodialysis. However, limitations in most of the above studies include the small sample size, the isolated measurements of the biomarker, the lack of precision regarding the time of NT-proBNP measurement in some studies, and the potential biases related to the methods used for PEW assessment. Factors indicating the presence of PEW can also be induced by inflammatory processes. Thus, the clinical context should be taken into account for the interpretation of elevated NT-proBNP levels. Since high NTproBNP is primarily a marker of cardiac dysfunction, the increased levels of the prohormone must draw attention to cardiac function but also to nutritional status. Nevertheless, we must highlight the need to evaluate the prognostic value of NT-proBNP for malnutrition in hemodialysis in further studies.

\section{Acronyms}

BIA: $\quad$ Bioimpedance analysis

BMI: $\quad$ Body mass index

BNP: $\quad$ Brain natriuretic peptide

CKD: $\quad$ Chronic kidney disease

ESRD: $\quad$ End-stage renal disease

HD: Hemodialysis

hsCRP: High-sensitive C-reactive protein

IDGW: Interdialytic weight gain

ISRNM: International Society of Renal Nutrition and Metabolism

MIS: $\quad$ Malnutrition-inflammation score

NP: $\quad$ Natriuretic peptides

nPCR: Normalized protein catabolic rate

NT- N-terminal probrain natriuretic peptide

proBNP:

\%CGR: Percentage creatinine generation rate

PEW: $\quad$ Protein energy wasting

SGA: $\quad$ Subjective global assessment. 


\section{Conflicts of Interest}

The authors declare no conflicts of interest.

\section{Acknowledgments}

The authors would like to acknowledge Mrs Jeanne Arjounin (Head of the library at the University Hospital Center, Guadeloupe) and Mr Peter Tucker (Medical Translator/ Editor for medical authors at University Hospitals in France and Belgium) for their support.

\section{References}

[1] L. Foucan, H. Merault, F. L. Velayoudom-Cephise, L. Larifla, C. Alecu, and J. Ducros, "Impact of protein energy wasting status on survival among Afro-Caribbean hemodialysis patients: a 3-year prospective study," Springerplus, vol. 4, p. 452, 2015.

[2] C. P. Kovesdy and K. Kalantar-Zadeh, "Why is protein-energy wasting associated with mortality in chronic kidney disease?," Seminars in Nephrology, vol. 29, no. 1, pp. 3-14, 2009.

[3] C. Kawagoe, Y. Sato, T. Toida et al., "N-terminal-pro-B-typenatriuretic peptide associated with 2-year mortality from both cardiovascular and non-cardiovascular origins in prevalent chronic hemodialysis patients," Renal Failure, vol. 40, no. 1, pp. 127-134, 2018.

[4] M. Aparicio, N. Cano, P. Chauveau et al., "Nutritional status of haemodialysis patients: a French national cooperative study. French study group for nutrition in dialysis," Nephrology Dialysis Transplantation, vol. 14, no. 7, pp. 1679-1686, 1999.

[5] K. Kalantar-Zadeh, T. A. Ikizler, G. Block, M. M. Avram, and J. D. Kopple, "Malnutrition-inflammation complex syndrome in dialysis patients: causes and consequences," American Journal of Kidney Diseases, vol. 42, no. 5, pp. 864-881, 2003.

[6] T. G. Yandle, "Biochemistry of natriuretic peptides," Journal of Internal Medicine, vol. 235, no. 6, pp. 561-576, 1994.

[7] J. A. Doust, E. Pietrzak, A. Dobson, and P. Glasziou, "How well does B-type natriuretic peptide predict death and cardiac events in patients with heart failure: systematic review," $B M J$, vol. 330, no. 7492, p. 625, 2005.

[8] J. L. Januzzi, R. van Kimmenade, J. Lainchbury et al., "NTproBNP testing for diagnosis and short-term prognosis in acute destabilized heart failure: an international pooled analysis of 1256 patients: the International Collaborative of NT-proBNP Study," European Heart Journal, vol. 27, no. 3, pp. 330-337, 2006.

[9] G. C. Fonarow, W. F. Peacock, C. O. Phillips, M. M. Givertz, and M. Lopatin, "Admission B-type natriuretic peptide levels and in-hospital mortality in acute decompensated heart failure," Journal of the American College of Cardiology, vol. 49, no. 19, pp. 1943-1950, 2007.

[10] M. Volpe, S. Rubattu, and J. Burnett, "Natriuretic peptides in cardiovascular diseases: current use and perspectives," European Heart Journal, vol. 35, no. 7, pp. 419-425, 2014.

[11] A. Bednarek-Skublewska, W. Zaluska, and A. Ksiazek, "The relationship between serum level of $\mathrm{N}$-terminal pro-B-type natriuretic peptide and nutritional status, and inflammation in chronic hemodialysis patients," Clinical Nephrology, vol. 73, no. 1, pp. 14-20, 2010.

[12] J. Ducros, L. Larifla, H. Merault, and L. Foucan, "NT-proBNP, cardiometabolic risk factors, and nutritional status in hemodialysis patients," International Journal of Nephrology, vol. 2017, Article ID 1312547, 8 pages, 2017.
[13] Q. Guo, P. Bárány, A. R. Qureshi et al., "N-terminal pro-brain natriuretic peptide independently predicts protein energy wasting and is associated with all-cause mortality in prevalent HD patients," American Journal of Nephrology, vol. 29, no. 6, pp. 516-523, 2009.

[14] M. Ikeda, H. Honda, K. Takahashi, K. Shishido, and T. Shibata, "N-terminal pro-B-type natriuretic peptide as a biomarker for loss of muscle mass in prevalent hemodialysis patients," PLoS One, vol. 11, no. 11, Article ID e0166804, 2016.

[15] Y.-J. Lee, B. G. Song, M. S. Kim et al., "Interaction of malnutrition, N-terminal pro-B-type natriuretic peptide and ventricular remodeling in patients on maintenance hemodialysis," Clinical Nephrology, vol. 79, no. 4, pp. 253-260, 2013.

[16] K. Schwermer, K. Hoppe, D. Radziszewska et al., "N terminal proBtype natriuretic peptide as a marker of hypervolemia and predictor of increased mortality in patients on hemodialysis," Polish Archives of Internal Medicine, vol. 125, no. 7-8, pp. 560-569, 2015.

[17] S. Snaedal, A. R. Qureshi, J. J. Carrero, O. Heimbürger, P. Stenvinkel, and P. Bárány, "Determinants of N-terminal pro-brain natriuretic peptide variation in hemodialysis patients and prediction of survival," Blood Purification, vol. 37, no. 2, pp. 138-145, 2014.

[18] T. A. McDonagh, S. Holmer, I. Raymond, A. Luchner, P. Hildebrant, and H. J. Dargie, "NT-proBNP and the diagnosis of heart failure: a pooled analysis of three European epidemiological studies," European Journal of Heart Failure, vol. 6, no. 3, pp. 269-273, 2004.

[19] J. A. Schaub, S. G. Coca, D. G. Moledina, M. Gentry, J. M. Testani, and C. R. Parikh, "Amino-terminal pro-B-type natriuretic peptide for diagnosis and prognosis in patients with renal dysfunction: a systematic review and meta-analysis," JACC: Heart Failure, vol. 3, no. 12, pp. 977-989, 2015.

[20] L. H. Madsen, S. Ladefoged, P. Corell et al., "N-terminal pro brain natriuretic peptide predicts mortality in patients with end-stage renal disease in hemodialysis," Kidney International, vol. 71, no. 6, pp. 548-554, 2007.

[21] E. Laveborn, K. Lindmark, M. Skagerlind, and B. Stegmayr, "NT-proBNP and troponin T levels differ after haemodialysis with a low versus high flux membrane," The International Journal of Artificial Organs, vol. 38, no. 2, pp. 69-75, 2015.

[22] J. Racek, H. Králová, L. Trefil, D. Rajdl, and J. Eiselt, "Brain natriuretic peptide and N-terminal proBNP in chronic haemodialysis patients," Nephron Clinical Practice, vol. 103, no. 4, pp. c162-c172, 2006.

[23] G. Dautin, S. Boudjeltia, Z. Soltani, P. Gambert, and L. Duvillard, "The changes in NT-proBNP plasma concentrations during dialysis are highly dependent of the dialysis membrane ultrafiltration coefficient," Clinica Chimica Acta, vol. 376, no. 1-2, pp. 237-239, 2007.

[24] C. Sommerer, S. Heckele, V. Schwenger et al., "Cardiac biomarkers are influenced by dialysis characteristics," Clinical Nephrology, vol. 68, no. 6, pp. 392-400, 2007.

[25] M. Antlanger, M. Hecking, M. Haidinger et al., "Fluid overload in hemodialysis patients: a cross-sectional study to determine its association with cardiac biomarkers and nutritional status," BMC Nephrology, vol. 14, no. 1, p. 266, 2013.

[26] J. Booth, J. Pinney, and A. Davenport, "N-terminal proBNPmarker of cardiac dysfunction, fluid overload, or malnutrition in hemodialysis patients?," Clinical Journal of the American Society of Nephrology, vol. 5, no. 6, pp. 1036-1040, 2010.

[27] A. Nongnuch, K. Panorchan, and A. Davenport, "Predialysis NTproBNP predicts magnitude of extracellular volume overload in haemodialysis patients," American Journal of Nephrology, vol. 40, no. 3, pp. 251-257, 2014. 
[28] B. D. Westenbrink, T. K. Hovinga, W. D. Kloppenburg, N. J. Veeger, and W. M. Janssen, "B-type natriuretic peptide and interdialytic fluid retention are independent and incremental predictors of mortality in hemodialysis patients," Clinical Nephrology, vol. 76, no. 5, pp. 373-379, 2011.

[29] L. H. Jacobs, J. J. van de Kerkhof, A. M. Mingels et al., "Inflammation, overhydration and cardiac biomarkers in haemodialysis patients: a longitudinal study," Nephrology Dialysis Transplantation, vol. 25, no. 1, pp. 243-248, 2010.

[30] A. L. Steiber, K. Kalantar-Zadeh, D. Secker, M. McCarthy, A. Sehgal, and L. McCann, "Subjective global assessment in chronic kidney disease: a review," Journal of Renal Nutrition, vol. 14, no. 4, pp. 191-200, 2004.

[31] K. Kalantar-Zadeh, J. D. Kopple, G. Block, and M. H. Humphreys, "A malnutrition-inflammation score is correlated with morbidity and mortality in maintenance hemodialysis patients," American Journal of Kidney Diseases, vol. 38, no. 6, pp. 1251-1263, 2001.

[32] D. Fouque, K. Kalantar-Zadeh, J. Kopple et al., “A proposed nomenclature and diagnostic criteria for protein-energy wasting in acute and chronic kidney disease," Kidney International, vol. 73, no. 4, pp. 391-398, 2008.

[33] Guidelines from the National Kidney Foundation, "Clinical practice guidelines for nutrition in chronic renal failure. K/ DOQI, National Kidney Foundation," American Journal of Kidney Diseases, vol. 35, no. 6, pp. S1-S140, 2000.

[34] S. Collins, "A heart-adipose tissue connection in the regulation of energy metabolism," Nature Reviews Endocrinology, vol. 10, no. 3, pp. 157-163, 2014.

[35] T. J. Wang, M. G. Larson, D. Levy et al., "Impact of obesity on plasma natriuretic peptide levels," Circulation, vol. 109, no. 5, pp. 594-600, 2004.

[36] L. H. Zheng, L. M. Wu, Y. Yao et al., "Impact of body mass index on plasma N-terminal ProB-type natriuretic peptides in Chinese atrial fibrillation patients without heart failure," PLoS One, vol. 9, no. 8, Article ID e105249, 2014.

[37] M. R. Mehra, P. A. Uber, M. H. Park et al., "Obesity and suppressed B-type natriuretic peptide levels in heart failure," Journal of the American College of Cardiology, vol. 43, no. 9, pp. 1590-1595, 2004.

[38] S. R. Das, M. H. Drazner, D. L. Dries et al., "Impact of body mass and body composition on circulating levels of natriuretic peptides," Circulation, vol. 112, no. 14, pp. 2163-2168, 2005.

[39] H. Trimarchi, A. Muryan, V. Campolo-Girard et al., "Elevated pro-brain natriuretic peptide, troponin $\mathrm{T}$ and malnutrition inflammatory score in chronic hemodialysis patients with overt cardiovascular disease," Nephron Clinical Practice, vol. 117, no. 3, pp. c198-c205, 2011.

[40] E. M. Changchien, S. Ahmed, F. Betti et al., "B-type natriuretic peptide increases after gastric bypass surgery and correlates with weight loss," Surgical Endoscopy, vol. 25, no. 7, pp. 2338-2343, 2011.

[41] A. Chen-Tournoux, A. M. Khan, A. L. Baggish et al., "Effect of weight loss after weight loss surgery on plasma N-terminal pro-B-type natriuretic peptide levels," The American Journal of Cardiology, vol. 106, no. 10, pp. 1450-1455, 2010.

[42] A. M. Gabrielsen, T. Omland, M. Brokner et al., "The effect of surgical and non-surgical weight loss on N-terminal pro-Btype natriuretic peptide and its relation to obstructive sleep apnea and pulmonary function," BMC Research Notes, vol. 9, no. 1, p. 440, 2016.

[43] N. Abrahamsson, B. E. Engström, M. Sundbom, and F. A. Karlsson, "Gastric bypass surgery elevates NT-ProBNP levels," Obesity Surgery, vol. 23, no. 9, pp. 1421-1426, 2013.
[44] A. Sabatino, G. Regolisti, M. Delsante et al., "Noninvasive evaluation of muscle mass by ultrasonography of quadriceps femoris muscle in end-stage renal disease patients on hemodialysis," Clinical Nutrition, vol. 38, no. 3, pp. 1232-1239, 2019.

[45] F. Spannella, F. Giulietti, G. Cocci et al., "N-terminal pro B-Type natriuretic peptide is inversely correlated with low density lipoprotein cholesterol in the very elderly," Nutrition, Metabolism and Cardiovascular Diseases, vol. 28, no. 6, pp. 629-635, 2018.

[46] V. S. Lim and J. D. Kopple, "Protein metabolism in patients with chronic renal failure: role of uremia and dialysis," Kidney International, vol. 58, no. 1, pp. 1-10, 2000.

[47] R. A. Ward, M. J. Shirlow, J. M. Hayes, G. V. Chapman, and P. C. Farrell, "Protein catabolism during hemodialysis," The American Journal of Clinical Nutrition, vol. 32, no. 12, pp. 2443-2449, 1979.

[48] J. J. Carrero, A. Nakashima, A. R. Qureshi et al., "Proteinenergy wasting modifies the association of ghrelin with inflammation, leptin, and mortality in hemodialysis patients," Kidney International, vol. 79, no. 7, pp. 749-756, 2011.

[49] J. P. Bertinchant, "Brain natriuretic peptide (BNP) and N-terminal-pro BNP in chronic haemodialysed renal failure," Archives Des Maladies Du Coeur Et Des Vaisseaux, vol. 97, no. 9, pp. 881-888, 2004.

[50] M. J. E. Dekker, C. Konings, B. Canaud et al., "Interactions between malnutrition, inflammation, and fluid overload and their associations with survival in prevalent hemodialysis patients," Journal of Renal Nutrition, vol. 28, no. 6, pp. 435-444, 2018.

[51] B. R. Don and G. Kaysen, "Poor nutritional status and inflammation: serum albumin: relationship to inflammation and nutrition," Seminars in Dialysis, vol. 17, no. 6, pp. 432-437, 2004.

[52] K. Kalantar-Zadeh, E. Streja, M. Z. Molnar et al., "Mortality prediction by surrogates of body composition: an examination of the obesity paradox in hemodialysis patients using composite ranking score analysis," American Journal of Epidemiology, vol. 175, no. 8, pp. 793-803, 2012.

[53] M. Lafontan, C. Moro, M. Berlan, F. Crampes, C. Sengenes, and J. Galitzky, "Control of lipolysis by natriuretic peptides and cyclic GMP," Trends in Endocrinology \& Metabolism, vol. 19, no. 4, pp. 130-137, 2008.

[54] C. Sengenes, M. Berlan, I. De Glisezinski, M. Lafontan, and I. Galitzky, "Natriuretic peptides: a new lipolytic pathway in human adipocytes," The FASEB Journal, vol. 14, no. 10, pp. 1345-1351, 2000.

[55] S. Engeli, A. L. Birkenfeld, P.-M. Badin et al., "Natriuretic peptides enhance the oxidative capacity of human skeletal muscle," Journal of Clinical Investigation, vol. 122, no. 12, pp. 4675-4679, 2012.

[56] G. Vila, G. Grimm, M. Resl et al., "B-type natriuretic peptide modulates ghrelin, hunger, and satiety in healthy men," $D i$ abetes, vol. 61, no. 10, pp. 2592-2596, 2012.

[57] C. C. Rusu, S. Racasan, D. Moldovan et al., "Ghrelin and acyl ghrelin levels are associated with inflammatory and nutritional markers and with cardiac and vascular dysfunction parameters in hemodialysis patients," International Urology and Nephrology, vol. 50, no. 10, pp. 1897-1906, 2018.

[58] M. Muscaritoli, A. Molfino, M. G. Chiappini et al., "Anorexia in hemodialysis patients: the possible role of des-acyl ghrelin," American Journal of Nephrology, vol. 27, no. 4, pp. 360-365, 2007.

[59] S. S. Gunta and R. H. Mak, "Ghrelin and leptin pathophysiology in chronic kidney disease," Pediatric Nephrology, vol. 28, no. 4, pp. 611-616, 2013. 